\title{
Molecular dynamic simulation of mutated $\beta$-catenin in solid pseudopapillary neoplasia of the pancreas
}

\author{
VAROMYALIN TIPMANEE ${ }^{1}$, NAWANWAT C. PATTARANGGOON ${ }^{1}$, KANET KANJANAPRADIT ${ }^{2}$, \\ JIRAKRIT SAETANG ${ }^{1}$ and SURASAK SANGKHATHAT ${ }^{1,3}$
}

\author{
Departments of ${ }^{1}$ Biomedical Science, ${ }^{2}$ Pathology and ${ }^{3}$ Surgery, Faculty of Medicine,
}

Prince of Songkla University, Hat Yai, Songkhla 90110, Thailand

Received August 31, 2016; Accepted January 22, 2018

DOI: $10.3892 / \mathrm{ol} .2018 .8490$

\begin{abstract}
Solid pseudopapillary neoplasia of the pancreas (SPN) is a rare pancreatic neoplasm that frequently harbors mutations in catenin $\beta 1$ (CTNNB1, encoding $\beta$-catenin) as a part of its molecular pathogenesis. Mutations to $C T N N B 1$ reported in SPN usually occur at the serine/threonine phosphorylation sites, including codons 33,37 and 41, and the flanking residues of codon 33. On analysis of 3 cases of SPN, mutations to CTNNB1 were detected in codon 32 (D32A and D32Y). As this residue, aspartic acid, is not a direct phosphorylation site of the protein, molecular modeling tools were used to predict the influence of these mutations on the protein structure of $\beta$-catenin. A total of three MD simulations (wild-type, D32A, and D32Y) were performed to visualize the conformations of $\beta$-catenin under in vivo, aqueous-phase conditions at $37^{\circ} \mathrm{C}$. In the wild-type protein, the secondary structure of residues P16-H28 remained helical; we therefore hypothesized that the helical structure of this protein fragment (residues M11-G50) was necessary for phosphorylation of S33 phosphorylation. The loss of the secondary structure in P16-H28 was observed in D32A, losing its helical structure and becoming a turn; however, in the D32Y mutant, the helical structure remained. The present demonstrated that structural changes in the mutated $\beta$-catenin protein at D32 could potentially explain the mechanism behind its defective phosphorylation in the pathogenesis of SPN.
\end{abstract}

\section{Introduction}

Solid pseudopapillary neoplasia of the pancreas (SPN) is a rare pancreatic neoplasm accounting for $<2 \%$ of pancreatic exocrine tumors. SPN usually occurs in young female patients

Correspondence to: Dr Surasak Sangkhathat, Department of Surgery, Faculty of Medicine, Prince of Songkla University, 15 Kanjanawanit Road, Hat Yai, Songkhla 90110, Thailand

E-mail: surasak.sa@psu.ac.th

Key words: solid pseudopapillary neoplasia of the pancreas, catenin $\beta 1$, molecular dynamics simulation, $\beta$-catenin during the second to third decade of life (1). In the majority of cases, the patient presents with a mixed cystic-solid mass in any region of the pancreas, which may compress adjacent organs and cause symptoms (2). SPN is generally regarded as a low-grade malignant tumor that is confined to the pancreas, for which en-bloc resection is the primary therapeutic method (3). The prognosis is generally favorable, except for patients with invasion and metastasis at the time of diagnosis, which is reported in $\sim 5 \%$ of cases $(4,5)$.

Histopathologically, SPN displays solid pseudopapillary areas intermixed with cystic regions, and consist of uniform polygonal-shaped cells with oval nuclei and abundant cytoplasm, with occasional pleomorphism and mitosis (6). The majority of SPNs are marked with neuron-specific enolase, vimentin and $\alpha 1$-antitrypsin and are immunohistochemically negative for cytokeratin AE1/AE3 (3). In addition, Ki-67 immunoreactivity is associated with tumor aggressiveness and poorer patient prognosis. A recent study has revealed that the nuclear accumulation of the $\beta$-catenin protein is one of the pathological hallmarks of SPN (7). Further investigations reported somatic mutations to catenin $\beta 1(C T N N B 1)$ in the tumor tissue, with the majority being point mutations at serine/threonine residues that are phosphorylation sites of glycogen synthase kinase-3 $\beta$ (GSK-3 $\beta$ ), including at codons 33, 37 and 41, and the flanking residues of codon 33 (codons 32 and 34) (8). The most common mutation was reported at codon $32(8)$.

$\beta$-catenin, encoded by $C T N N B 1$, is centrally involved in the Wnt signaling pathway, which serves physiological roles in embryonic organ development (9). In differentiated cells, the cytosolic level of $\beta$-catenin is kept low by a ubiquitination process driven by phosphorylation of $\beta$-catenin at its clustered serine/threonine residues in exon 3 by casein kinase 1 (CK1), and glycogen synthase kinase 3 (GSK3), which are the scaffolding proteins that serve a role in $\beta$-catenin ubiquitination and proteasomal degradation (9). Mutations involving these phosphorylation sites are involved in the molecular pathogenesis of various pediatric embryonal tumors, including hepatoblastoma, Wilms tumor, medulloblastoma and pancreatoblastoma (10-12). Codon 32, encoding for aspartic acid, is not the phosphorylation target itself. However, point mutations at Asp32 have been reported in various types of human cancer, including SPN (8). The juxtaposition of Asp32 mutation with Ser33 may result in conformational changes that prevent 
effective phosphorylation, hence the cytosolic retention of $\beta$-catenin and its translocation into the nucleus (13).

Functional genetic studies focusing on codon 32 revealed a reduction in ubiquitination activity in D32G, D32N and D32Y mutants when compared to the wild-type sequence $(13,14)$. However, details regarding structural changes caused by codon 32 mutations have not been purposed. The present study investigated mutations to CTNNB1 detected in samples from three patients SPN and used molecular dynamics (MD) simulation to attempt to predict alterations to protein conformations caused by the mutations.

\section{Materials and methods}

Samples and polymerase chain reaction. The present study was approved by the Research Ethics Committee of the Faculty of Medicine, Prince of Songkla University (Hat Yai, Thailand) and patients provided written informed consent agreeing to their inclusion. Snap-frozen tumor specimens from three patients with SPN that underwent surgical resection in Songklanagarind Hospital were retrieved for DNA extraction. The cases included 1 male and 2 females, aged 12, 13 and 61 years, respectively. DNA extraction was done using GeneJET genomic DNA purification kit (Thermo Fisher Scientific, Inc., Waltham, MA, USA), following manufacturer's protocol. A mutation study covering the exon 2-4 of CTNNB1 was performed by polymerase chain reaction and direct nucleotide sequencing using 2 primer sets designed by Koch et al (15) and the PCR conditions reported by the study of Udatsu et al (16). PCR polymerase was performed by using TopTaq Master Mix kit (Qiagen, Hilden, Germany) with the condition as follows: $5 \mathrm{~min}$ at $95^{\circ} \mathrm{C}, 30$ cycles $(30 \mathrm{sec}$ at $95^{\circ} \mathrm{C}, 30 \mathrm{sec}$ at $58^{\circ} \mathrm{C}, 45 \mathrm{sec}$ at $72^{\circ} \mathrm{C}$ ) and $10 \mathrm{~min}$ at $72^{\circ} \mathrm{C}$. All amplicon was then purified by GeneJET PCR Purification kit (Thermo scientific, Massachusetts, USA). Nucleotide sequencing was performed by the Scientific Equipment Center, Prince of Songkla University. Mutations to CTNNB1 in each case involved codon 32, consisting of two incidences of D32A and one of D32Y (Table I).

Immunohistochemistry. Immunohistochemistry of the tumor tissue used the protocol presented in our previous work (17). Sections of $3-\mu \mathrm{m}$ thickness were stained using $\beta$-catenin monoclonal antibody (cat. no. 6B3; BD Biosciences, Franklin Lakes, NJ, USA) at a 1:1,000 dilution. Detection was then performed by using Bond Polymer Refine Detection system (Leica, Ltd., Milton Keynes, UK). This included all reagents: Peroxide blocking reagent (3-4\%), polymer anti-mouse poly-HRP-IgG $(<25 \mu \mathrm{g} / \mathrm{ml})$ containing $10 \%(\mathrm{v} / \mathrm{v})$ animal serum in tris-buffered saline/0.09\% ProClin $^{\text {TM }} 950$, DAB Part 1 (66 mM 3,3'-diaminobenzidine tetrahydrochloride hydrate, in a stabilizer solution), DAB Part B ( $\leq 0.1 \%(\mathrm{v} / \mathrm{v})$ hydrogen peroxide in a stabilizer solution), and hematoxylin. The protocol used in this study was performed as followed: After endogenous peroxidase blocking, slides were incubated at room temperature with primary antibody for $120 \mathrm{~min}$, followed by a $30 \mathrm{~min}$ incubation at room temperature with peroxidase labeled polymer conjugated to rabbit anti-mouse immunoglobulins. Color was then developed by the liquid 3,3'-diaminobenzidine tetrahydrochloride hydrate (DAB) chromogen. Counterstaining was performed with hematoxylin and imaged using a light microscope (magnification, $\mathrm{x} 20$ and $\mathrm{x} 40$ ). All procedures were performed according to the Bond Polymer Refine Detection system manufacturer protocol. Nuclear accumulation of $\beta$-catenin was demonstrated in the tissue of all cases (Fig. 1).

MD simulation of wild-type and mutated forms of $\beta$-catenin. To elucidate the role of the aforementioned mutations on $\beta$-catenin function, a three-dimensional (3D) structure was required. The wild-type $\beta$-catenin template was adopted from the first structure of an experimental nuclear magnetic resonance-derived structure from a rabbit (pdb code, 2G57), in which the sequence identity in the region of interest is identical to its human counterpart. As mutant structures of human $\beta$-catenin are not available, bioinformatics tools were introduced in the present study. In addition, MD simulation was performed to investigate the effects of point mutations on the protein conformation in detail.

The structure prediction was commenced using residues $11-50$ of the chosen $\beta$-catenin sequence. The residue numbers refer to those of the human $\beta$-catenin protein sequence (http://www.uniprot.org/uniprot/P35222). For each $\beta$-catenin (wild-type, D32A or D32Y), a secondary structure was independently predicted using two bioinformatics tools, PSIPRED Protein Sequence Analysis Workbench $(18,19)$ and NetSurfP version 1.1 (20). A prediction of the 3D structure of the wild type was performed using PEP-fold server (21-23), using the structure of rabbit $\beta$-catenin as a molecular template. The wild-type structure was finally chosen from 50 possible structures corresponding to the aforementioned predicted secondary structure predictions. For the mutant, the 3D structures of D32A and D32Y were constructed using the point mutation module of the Rosetta Backrub server (23), and the aforementioned wild-type structure was exploited as a template. The selection of the predicted structure was performed using the best result from 50 possible structures based on the highest prediction score.

Each constructed $\beta$-catenin structure was solvated in the TIP3P water rectangular box, 4,400 water molecules, with a distance of $12 \AA$ from the protein surface using the command from tleap module in AMBER16 package. Sodium chloride was then added into the system to make it equivalent to $0.15 \mathrm{M} \mathrm{NaCl}$ solution. Protonation states in all ionizable amino acid side chains were set at $\mathrm{pH}$ 7. The protein-solution system was modeled using AMBER10 force field, which was included in an AMBER 16 package (24). Prior to MD simulation, the system was energy-minimized to remove unusual inter-atomic contacts, using the steepest descent method for 2,000 steps. The system was then equilibrated in a constant number $(\mathrm{N})$, volume $(\mathrm{V})$, and temperature (T) (NVT) ensemble for $600 \mathrm{psec}$, where the protein was position-restrained using force constants of 250, 150, 100, 50,20 , and $10 \mathrm{kcal} / \mathrm{mol} / \AA^{2}$ for each $100 \mathrm{psec}$ simulation. A time step of $1 \mathrm{sec}$ was applied in each NVT run and a temperature of $310 \mathrm{~K}\left(37^{\circ} \mathrm{C}\right)$ was controlled using Langevin dynamics (25). The simulation was subsequently switched to an isobar/isothermal (constant number $(\mathrm{N})$, pressure $(\mathrm{P})$, and temperature (T); NPT) ensemble, with a temperature of $310 \mathrm{~K}$ and a pressure of $1 \mathrm{~atm}$, regulated by Berendsen 
Table I. Characteristics of the solid pseudopapillary neoplasias that were used in the present study.

\begin{tabular}{|c|c|c|c|}
\hline Patient & CTNNB1 mutation & Tumor details & Case data \\
\hline 1 & D32A & $\begin{array}{l}\text { A } 6-\mathrm{cm} \text { cyst at the pancreatic head } \\
\text { with pancreatic duct dilatation }\end{array}$ & $\begin{array}{l}12 \text {-year-old male, alive } \\
16 \text { years following surgery }\end{array}$ \\
\hline 2 & D32Y & $\begin{array}{l}\text { A } 3-\mathrm{cm} \text { cyst at the pancreatic body } \\
\text { with bilateral pleural effusion }\end{array}$ & $\begin{array}{l}61 \text {-year-old female, recurrence } \\
\text { at } 8 \text { years following surgery }\end{array}$ \\
\hline 3 & D32A & $\begin{array}{l}\text { A 5-cm well-encapsulated cyst at } \\
\text { the head of the pancreas }\end{array}$ & $\begin{array}{l}\text { 13-year-old female, alive } 4 \text { years } \\
\text { following surgery }\end{array}$ \\
\hline
\end{tabular}

CTNNB1, catenin $\beta 1$.

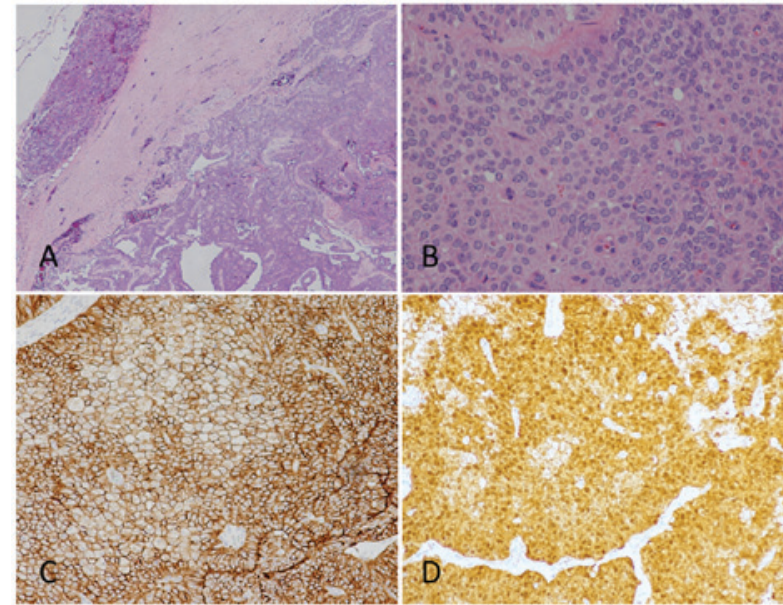

Figure 1. Representative histopathological images of solid papillary pseudotumor of pancreas. (A) Hematoxylin and eosin-stained tissue depicting encapsulated tumor with a predominately solid component, mixed with focal pseudocystic and pseudopapillary areas (x20 magnification). (B) The solid portion is composed of closely packed sheets of pseudopapillae. The tumor cells form distinct nodular mass. Mitosis is extremely rare (x40 magnification). (C and D) The tumor is positively stained for (C) CD56 and (D) $\beta$-catenin (x40 magnification).

algorithms (26). Short- and long-range interactions were computed using a $12 \AA$ cutoff and electrostatic forces were computed using Lennard-Jones 6-12 potential and Particle Mesh Ewald (PME) method (27), in which both are implemented in the AMBER16 simulation program. The NPT simulation was performed for $200 \mathrm{nsec}$, with a time step of 2 fsec. The energy minimization and MD simulations were performed using SANDER and PMEMD modules, respectively, using the AMBER 16 package (28). The first 100-nsec NPT simulation was omitted as an equilibrated phase and 100 equidistant snapshots from the last $100 \mathrm{nsec}$ were taken for analysis. The simulations of wild-type and mutant $\beta$-catenins followed an identical protocol. All structure visualization was performed using Visual Molecular Dynamics package version 1.9.1 (29) which is freely available online from Theoretical and Computational Biophysics Group of University of Illinois at Urbana Champaign.

\section{Results}

Each modeled tertiary structure of the $\beta$-catenin fragment (M11-G50) was in good agreement with the predicted

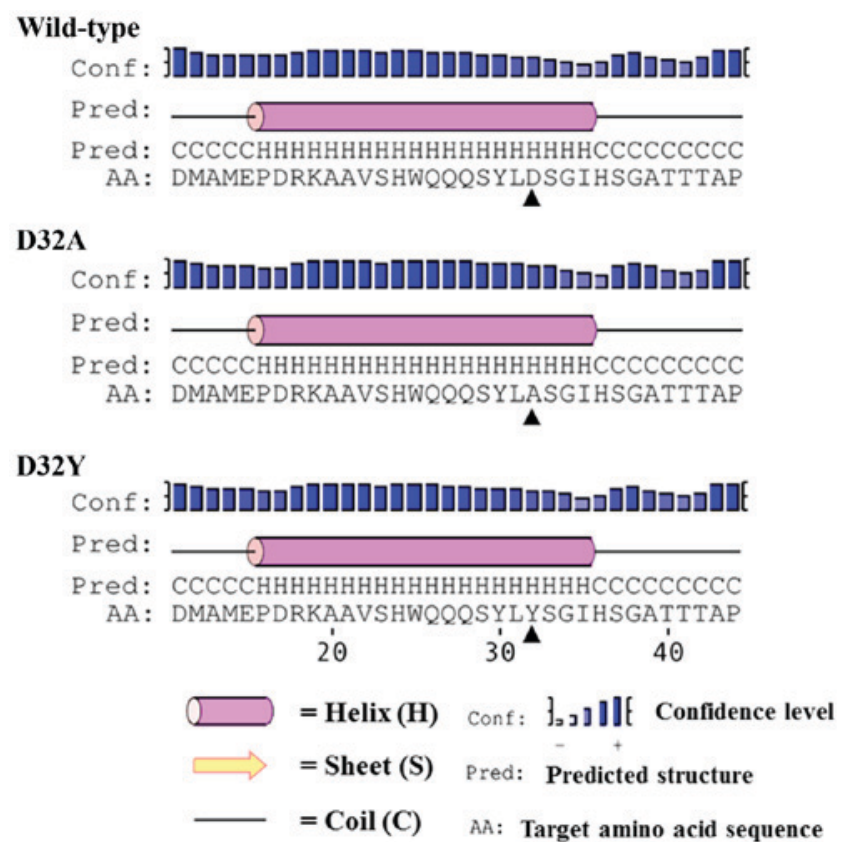

Figure 2. A predicted 3D structure of $\beta$-catenin from the protein sequence. A ribbon structure illustrates a $3 \mathrm{D}$ structure of wild-type or mutated $\beta$-catenin from a prediction using the PEP-FOLD webserver. The black triangle indicates the point mutation. All protein domains from P16 to $\mathrm{H} 35$ were predicted to form a helix, which verified the predicted $3 \mathrm{D}$ structure. 3D, three-dimensional.

secondary structure of its counterpart (Fig. 2). Since the protein fragment (M11-G50) also consists of S33, an important phosphorylation site for $\beta$-catenin functions (30-34), the simulation was performed with the hypothesis that the domain requires a specific conformation for phosphorylation to occur, and a point mutation could affect the phosphorylation by inducing a conformational change. Therefore, three MD simulations (wild-type, D32A, and D32Y) were performed to visualize the $\beta$-catenin conformations under in vivo, aqueous-phase conditions at $37^{\circ} \mathrm{C}$. Conformational abnormalities in mutant proteins may interfere with the phosphorylation of S33 and eventually contribute to $\beta$-catenin dysfunction. Additionally, the secondary structure of each residue in $\beta$-catenin residue was plotted against the simulation time to investigate the conformational changes of the 3D structure at the $\mathrm{S} 33$ site.

The stability of structural dynamics was observed via the Ramachandran plot from average structure, rather than the root-mean-square-displacement, owing to the high flexible 


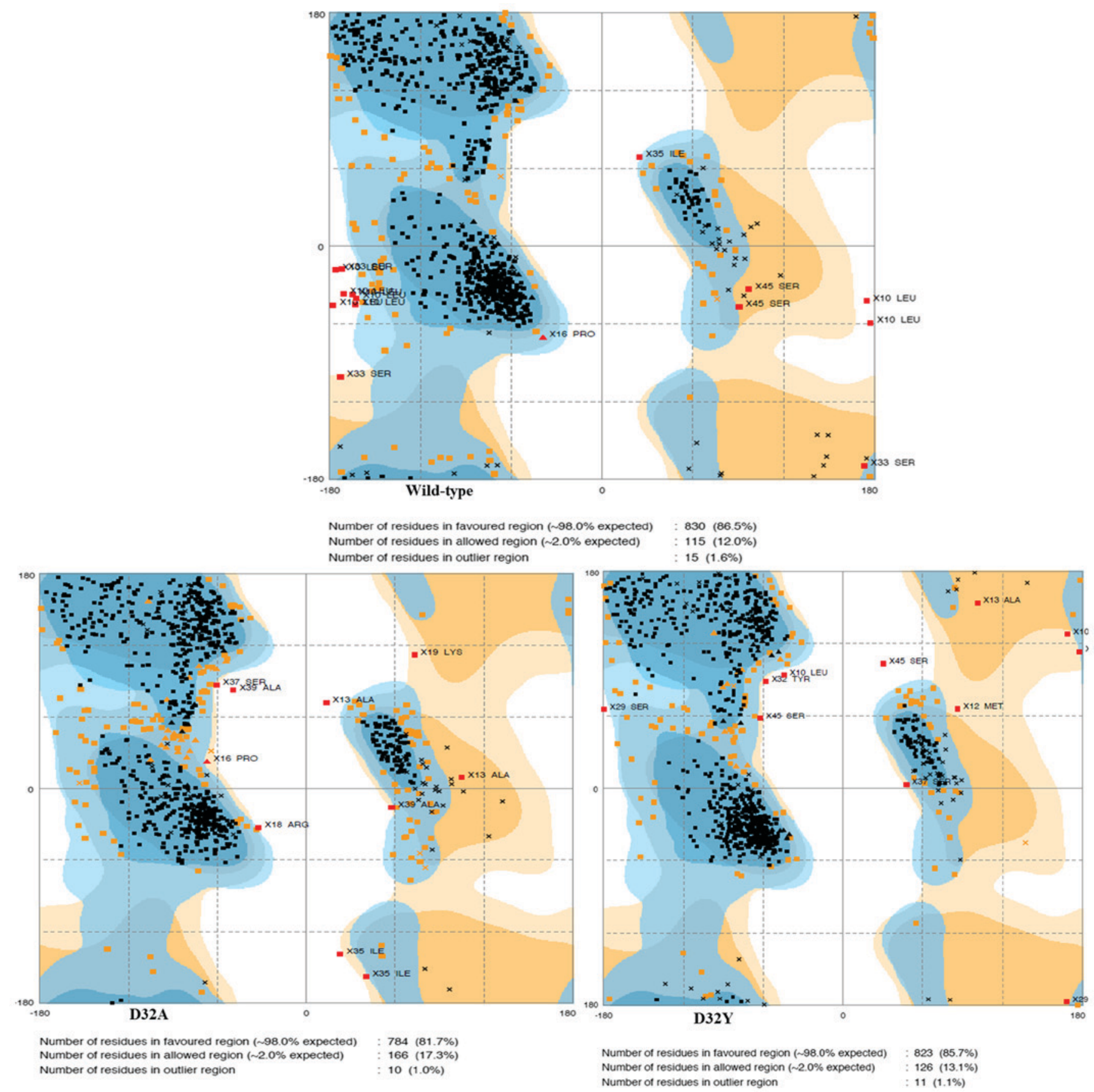

Figure 3. Ramachandran plot of $\beta$-catenin structure from the molecular dynamics simulation. A plot was obtained from the average of 20 snapshots from the 100-200-nsec trajectory. In all cases, $<1 \%$ of total amino acids fell within the outlier (disallowed) region. These data indicate the validity of simulated structure throughout the simulation.

coil in the fragment structure. The plot illustrated that $<1 \%$ of the overall amino acids in the dynamics trajectories fell into the outlier (disallowed) region (Fig. 3). Initially, the P16-H28 fragment was predicted to be a helical structure in the first place (Fig. 2). In the wild-type protein, after $100 \mathrm{nsec}$, the secondary structure of P16-H28 remained helical, similar to the starting structure (Fig. 4). These results indicated that the helical structure of this protein fragment $(\mathrm{P} 16-\mathrm{H} 28)$ is a prerequisite to $\mathrm{S} 33$ phosphorylation. A similar pattern of secondary structure was observed in the D32Y fragment (Fig. 5). This indicated that D32Y mutation, at least, may not affect phosphorylation activity via conformation distortion in this area. However, in the D32A mutant, a loss in the helical secondary structure of P16-H28 was observed, moving from a helical shape into a turn (Fig. 6). The D32A mutant therefore clearly possesses structural differences to the wild type $\beta$-catenin, and the mutation could enhance protein unfolding via alternation of the helical structure to interfere with the functional S33 position.

\section{Discussion}

SPN belongs to a group of human cancer types that occur in developing organs with somatic mutations to CTNNB1. 


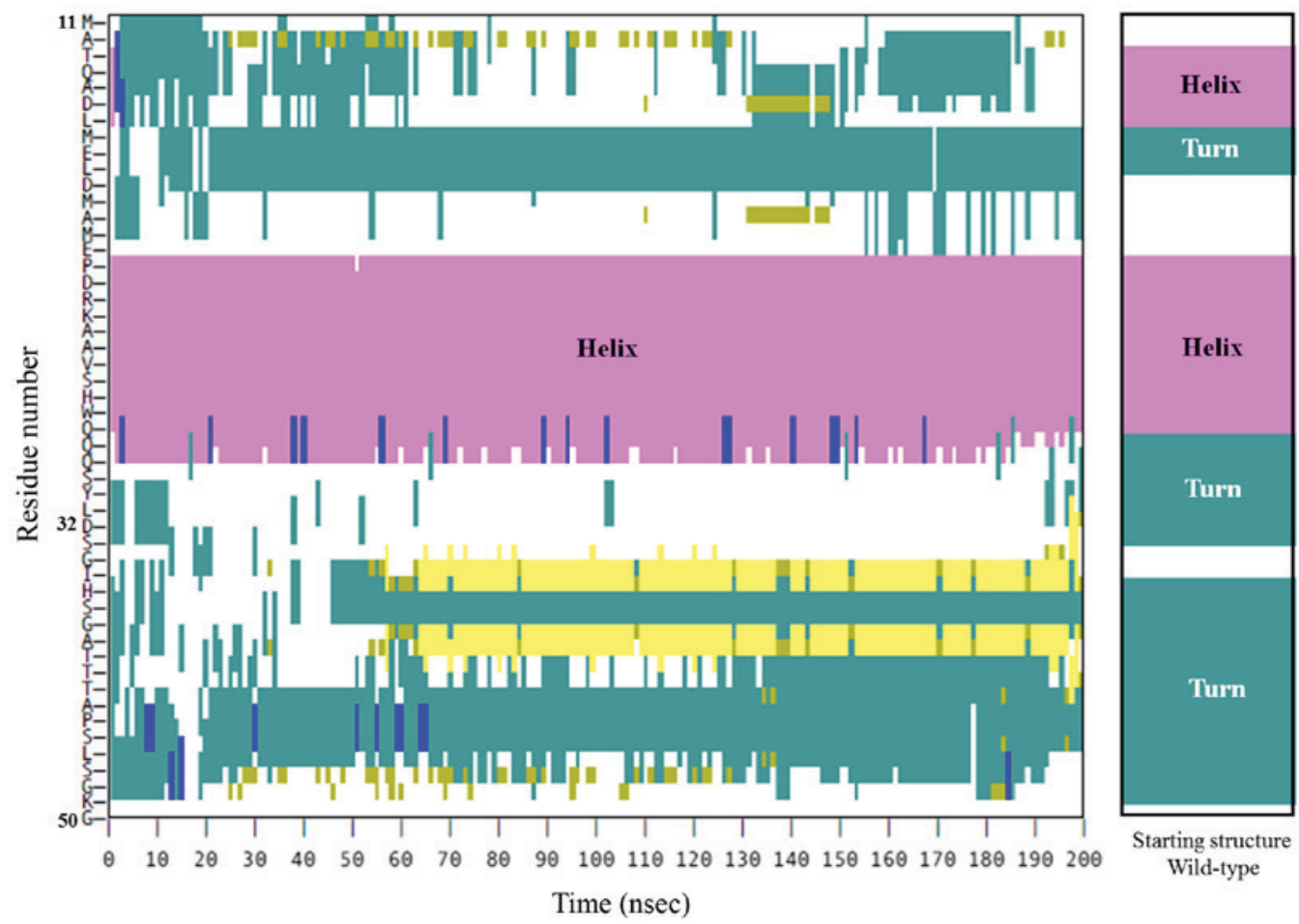

Figure 4. Secondary structure of wild-type $\beta$-catenin from molecular dynamics simulation, plotted against the simulation time. The number 32 indicates the position of the amino acid D32. The P16-H28 region remained helical throughout the simulation.

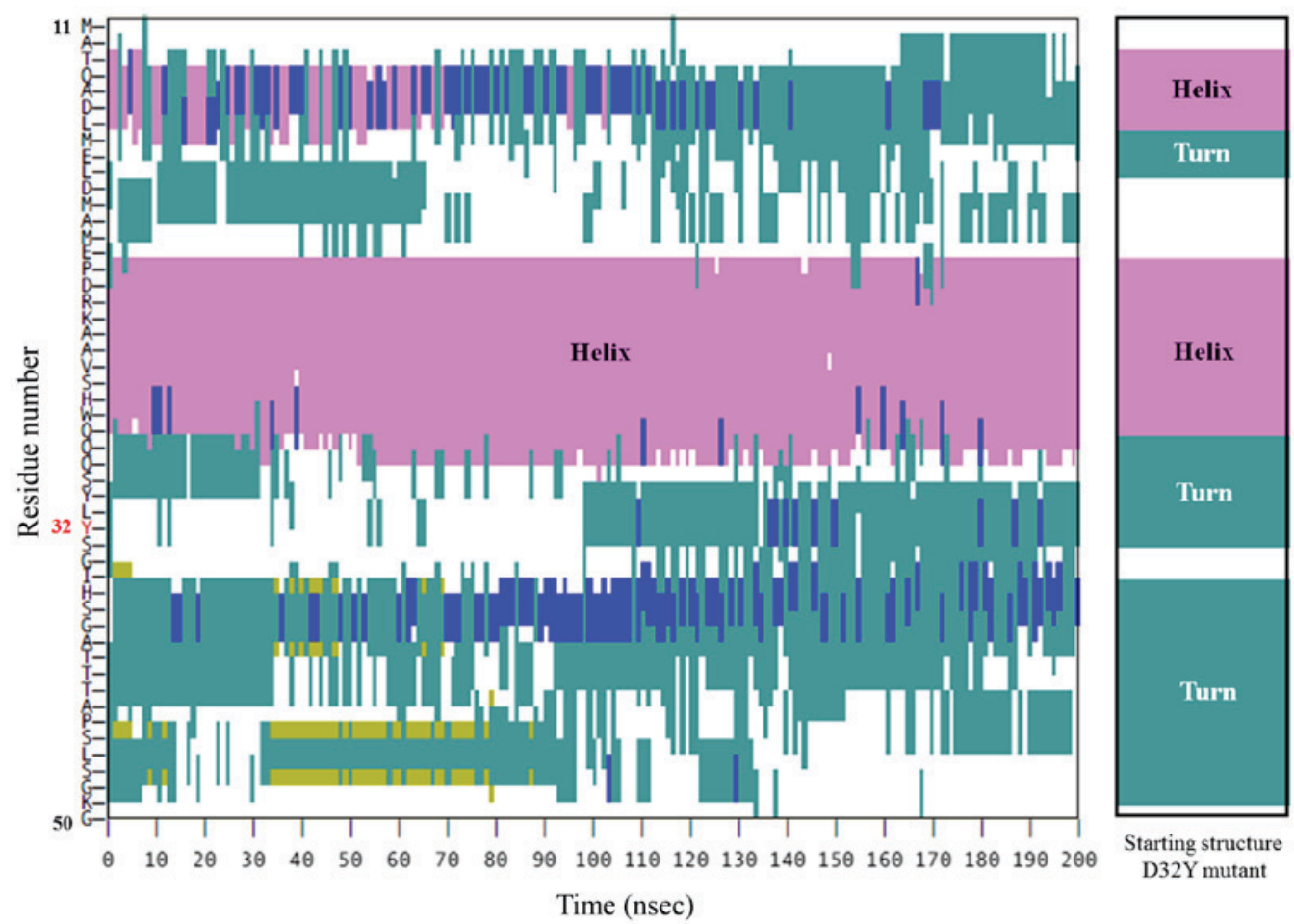

Figure 5. Secondary structure of D32Y $\beta$-catenin from molecular dynamics simulation, plotted against the simulation time. The number 32 indicates the position of the mutated amino acid Y32. The P16-H28 region remained helical throughout the simulation, similar to the wild-type structure.

Patterns of CTNNB1 mutation differ, and are specific to tumor types. In nephroblastoma, CTNNB1 mutations usually occur to codon 45 , whereas the majority of mutations in hepatoblastoma are large deletions involving exon 3 (10,35). Defective phosphorylation caused by $\beta$-catenin sequence alterations involves the priming phosphorylation sites for casein kinase I proteins, underlying the molecular mechanism of tumorigenesis of those neoplasms. Tumors containing mutations on the main phosphorylation sites are relatively fast-growing, invasive and respond well to 


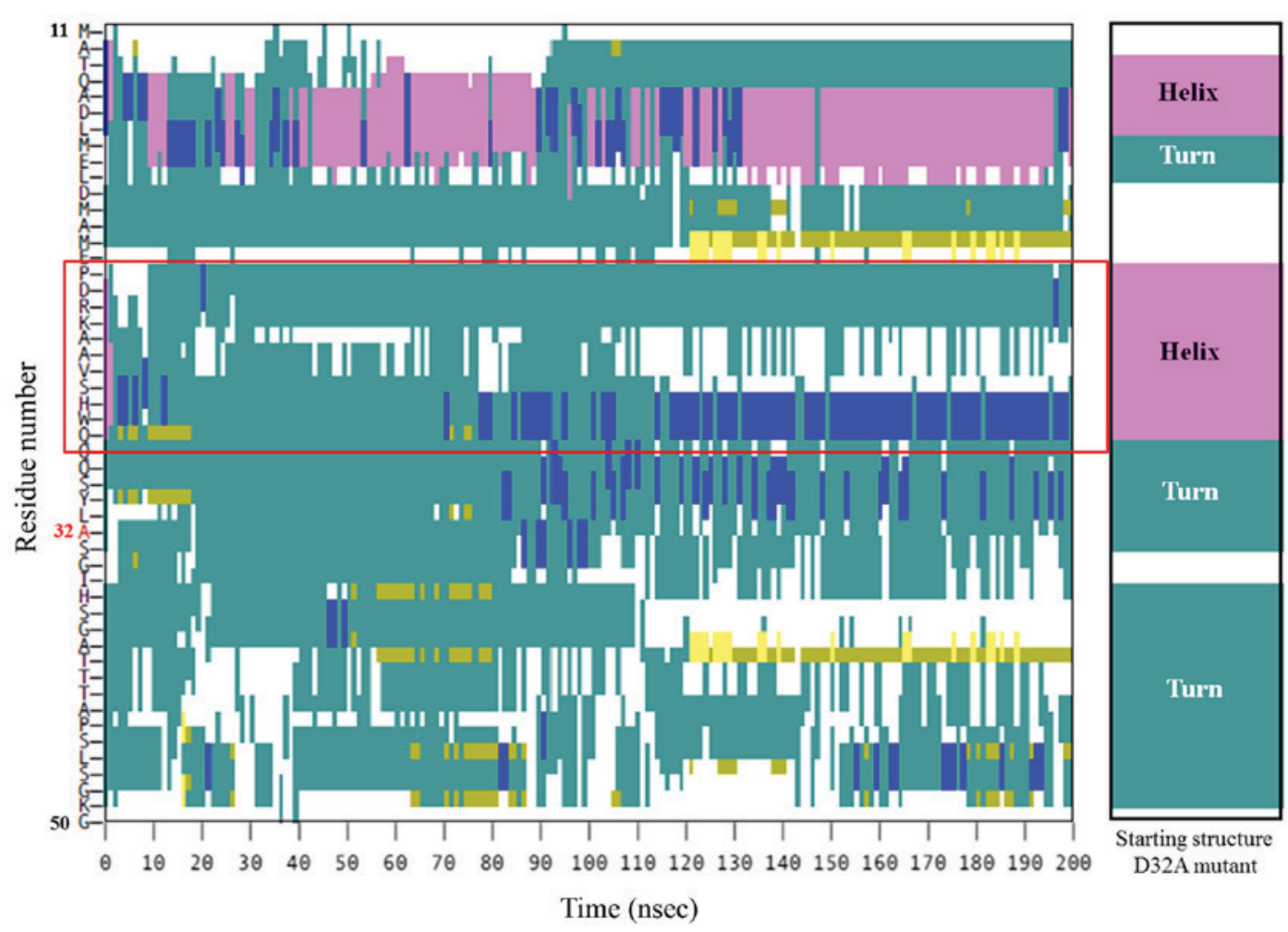

Figure 6. Secondary structure of D32A $\beta$-catenin from molecular dynamics simulation, plotted against the simulation time. The number 32 indicates the position of the mutated amino acid A32. The P16-H28 region, depicted with a red rectangular, lost its helical structure and became a turn following a simulation time of $<10 \mathrm{nsec}$. This result indicated D32A could induce a conformational change in $\beta$-catenin and lead to interference of phosphorylation.

chemotherapy. The mutation spots in medulloblastomas and pancreatoblastomas are confined to residues 33 and 37 , which are sequential phosphorylation sites for GSK-3 $\beta$ (10). Tumors harboring lesions on those secondary phosphorylation sites are usually found in older children and are relatively non-invasive (10).

Alterations to CTNNB1 codon 32 have been reported in rare tumor types, including SPN, pilomatrixomas and medulloblastomas (36-38). These tumors are relatively low-grade and rarely undergo distant metastasis. The study of Ellison et al (36) demonstrated that codon 32 was the most commonly mutated in childhood medulloblastoma. The current study detected mutations to this codon in each of the three cases studied. Together, this evidence supports the relevance of the molecular pathology in these rare tumors.

Three-dimensional molecular simulation is a useful computational tool for the prediction of the molecular structure of biomolecules, particularly proteins. The present study demonstrated that amino acid alterations to codon 32 tend to interfere with a helical structure within $\beta$-catenin. The MD simulations indicated that the D32A mutation was responsible for hindrance of phosphorylation at S33 in $\beta$-catenin by contributing to a loss of secondary structure, although D32Y may not act in the same way. Data from the structural prediction were consistent with a previous functional genetic study by Al-Fageeh et al (13), which demonstrated increased T-cell factor transactivation in a 293 cell culture model.

In conclusion, the present study used a computer-generated molecular structure model to successfully predicted conformational changes to $\beta$-catenin caused by point mutations at codon 32. These data indicate at the mechanism of tumorigenesis in patients with SPN that possess D32 $\beta$-catenin mutations.

\section{Acknowledgements}

Not applicable.

\section{Funding}

The study was partially supported by the Faculty of Medicine, Prince of Songkla University (Kho Hong, Thailand; grant no. 59-221-10-1).

\section{Availability of data and materials}

The analyzed data sets generated during the study are available from the corresponding author, on reasonable request.

\section{Authors' contributions}

VT and NCP performed in silico molecular modeling of the $\beta$-catenin protein. KK interpreted the pathological and immunohistochemistry results. JS performed the mutation study and wrote the manuscript. SS collected the clinical data.

\section{Ethics approval and consent to participate}

The present study was approved by the Research Ethics Committee of the Faculty of Medicine, Prince of Songkla 
University (Hat Yai, Thailand) and all patients provided written informed consent.

\section{Consent for publication}

Patients provided written informed consent for the publication of their data.

\section{Competing interests}

The authors declare that they have no competing interests.

\section{References}

1. Guo N, Zhou QB, Chen RF, Zou SQ, Li ZH, Lin Q, Wang J and Chen JS: Diagnosis and surgical treatment of solid pseudopapillary neoplasm of the pancreas: Analysis of 24 cases. Can J Surg 54: 368-374, 2011.

2. Papavramidis T and Papavramidis S: Solid pseudopapillary tumors of the pancreas: Review of 718 patients reported in English literature. J Am Coll Surg 200: 965-972, 2005.

3. Yagcı A, Yakan S, Coskun A, Erkan N, Yıldırım M, Yalcın E and Postaci H: Diagnosis and treatment of solid pseudopapillary tumor of the pancreas: Experience of one single institution from Turkey. World J Surg Oncol 11: 308, 2013.

4. Lee JS, Han HJ, Choi SB, Jung CW, Song TJ and Choi SY: Surgical outcomes of solid pseudopapillary neoplasm of the pancreas: A single institution's experience for the last ten years. Am Surg 78 216-219, 2012.

5. Ansari D, Elebro J, Tingstedt B, Ygland E, Fabricius M, Andersson B and Andersson R: Single-institution experience with solid pseudopapillary neoplasm of the pancreas. Scand J Gastroenterol 46: 1492-1497, 2011.

6. Adams AL, Siegal GP and Jhala NC: Solid pseudopapillary tumor of the pancreas: A review of salient clinical and pathologic features. Adv Anat Pathol 15: 39-45, 2008.

7. Huang SC, Ng KF, Yeh TS, Chang HC, Su CY and Chen TC: Clinicopathological analysis of $\beta$-catenin and Axin- 1 in solid pseudopapillary neoplasms of the pancreas. Ann Surg Oncol 19 (Suppl 3): S438-S446, 2012.

8. Kobayashi T, Ozasa M, Miyashita K, Saga A, Miwa K, Saito M, Morioka M, Takeuchi M, Takenouchi N, Yabiku T, et al: Large solid-pseudopapillary neoplasm of the pancreas with aberrant protein expression and mutation of $\beta$-catenin: A case report and literature review of the distribution of $\beta$-catenin mutation. Intern Med 52: 2051-2056, 2013.

9. MacDonald BT, Tamai K and He X: Wnt/beta-catenin signaling: Components, mechanisms, and diseases. Dev Cell 17: 9-26, 2009.

10. Koesters R and von Knebel Doeberitz M: The Wnt signaling pathway in solid childhood tumors. Cancer Lett 198: 123-138, 2003.

11. Sangkhathat S, Kusafuka T, Miao J, Yoneda A, Nara K, Yamamoto S, Kaneda Y and Fukuzawa M: In vitro RNA interference against $\beta$-catenin inhibits the proliferation of pediatric hepatic tumors. Int J Oncol 28: 715-722, 2006.

12. Sangkhathat S, Kanngurn S, Chaiyapan W, Gridist P and Maneechay W: Wilms' tumor 1 gene (WT1) is overexpressed and provides an oncogenic function in pediatric nephroblastomas harboring the wild-type WT1. Oncol Lett 1: 615-619, 2010.

13. Al-Fageeh M, Li Q, Dashwood WM, Myzak MC and Dashwood RH: Phosphorylation and ubiquitination of oncogenic mutants of beta-catenin containing substitutions at Asp32. Oncogene 23: 4839-4846, 2004.

14. Provost E, McCabe A, Stern J, Lizardi I, D'Aquila TG and Rimm DL: Functional correlates of mutation of the Asp32 and Gly34 residues of beta-catenin. Oncogene 24: 2667-2676, 2005.

15. Koch A, Denkhaus D, Albrecht S, Leuschner I, von Schweinitz D and Pietsch T: Childhood hepatoblastomas frequently carry a mutated degradation targeting box of the beta-catenin gene. Cancer Res 59: 269-273, 1999.

16. Udatsu Y, Kusafuka T, Kuroda S, Miao J and Okada A: High frequency of beta-catenin mutations in hepatoblastoma. Pediatr Surg Int 17: 508-512, 2001.
17. Wanitsuwan W, Kanngurn S, Boonpipattanapong T, Sangthong R and Sangkhathat S: Overall expression of beta-catenin outperforms its nuclear accumulation in predicting outcomes of colorectal cancers. World J Gastroenterol 14: 6052-6059, 2008.

18. Buchan DW, Minneci F, Nugent TC, Bryson K and Jones DT: Scalable web services for the PSIPRED protein analysis workbench. Nucleic Acids Res 41 (Web Server issue): W349-W357, 2013.

19. Jones DT: Protein secondary structure prediction based on position-specific scoring matrices. J Mol Biol 292: 195-202, 1999.

20. Petersen B, Petersen TN, Andersen P, Nielsen M and Lundegaard C: A generic method for assignment of reliability scores applied to solvent accessibility predictions. BMC Struct Biol 9: 51, 2009.

21. Maupetit J, Derreumaux P and Tuffery P: PEP-FOLD: An online resource for de novo peptide structure prediction. Nucleic Acids Res 37 (Web Server Issue): W498-W503, 2009.

22. Maupetit J, Derreumaux P and Tufféry P: A fast method for large-scale de novo peptide and miniprotein structure prediction. J Comput Chem 31: 726-738, 2010.

23. Thévenet P, Shen Y, Maupetit J, Guyon F, Derreumaux P and Tufféry P: PEP-FOLD: An updated de novo structure prediction server for both linear and disulfide bonded cyclic peptides. Nucleic Acids Res 40 (Web Server Issue): W288-W293, 2012.

24. Case DA, Cerutti DS, Cheatham III TE, Darden TA, Duke RE, Giese TJ, Gohlke H, Goetz AW, Greene D, Homeyer N, et al: AMBER 2017. University of California, SF, 2017.

25. Pastor RW, Brooks BR and Szabo A: An analysis of the accuracy of Langevin and molecular dynamics algorithms. Mol Phys 65: $1409-1419,1988$

26. Berendsen HJC, Postma JPM, Gunsteren WF van, DiNola A and Haak JR: Molecular dynamics with coupling to an external bath. J Chem Phys 81: 3684-3690, 1984.

27. Darden TA and Pedersen LG: Molecular modeling: An experimental tool. Environ Health Perspect 101: 410-412, 1993.

28. Case DA, Darden TA, Cheatham TE III, Simmerling CL, Wang J, Duke RE, Luo R, Walker RC, Zhang W, Merz KM, et al: AMBER 12. University of California, SF, 2012.

29. Humphrey W, Dalke A and Schulten K: VMD: Visual molecular dynamics. J Mol Graph 14: 33-38, 27-28, 1996.

30. Morin PJ, Sparks AB, Korinek V, Barker N, Clevers H, Vogelstein B and Kinzler KW: Activation of beta-catenin-Tcf signaling in colon cancer by mutations in beta-catenin or APC. Science 275: 1787-1790, 1997.

31. Chan EF, Gat U, McNiff JM and Fuchs E: A common human skin tumour is caused by activating mutations in beta-catenin. Nat Genet 21: 410-413, 1999.

32. Legoix P, Bluteau O, Bayer J, Perret C, Balabaud C, Belghiti J, Franco D, Thomas G, Laurent-Puig P and Zucman-Rossi J: Beta-catenin mutations in hepatocellular carcinoma correlate with a low rate of loss of heterozygosity. Oncogene 18: 4044-4046, 1999.

33. Huang H, Mahler-Araujo BM, Sankila A, Chimelli L, Yonekawa Y, Kleihues $\mathrm{P}$ and Ohgaki H: APC mutations in sporadic medulloblastomas. Am J Pathol 156: 433-437, 2000.

34. van Noort $\mathbf{M}$, van de Wetering $\mathbf{M}$ and Clevers $\mathrm{H}$ : Identification of two novel regulated serines in the $\mathrm{N}$ terminus of beta-catenin. Exp Cell Res 276: 264-272, 2002.

35. Koesters R, Ridder R, Kopp-Schneider A, Betts D, Adams V, Niggli F, Briner J and von Knebel Doeberitz M: Mutational activation of the beta-catenin proto-oncogene is a common event in the development of Wilms' tumors. Cancer Res 59: 3880-3882, 1999.

36. Ellison DW, Onilude OE, Lindsey JC, Lusher ME, Weston CL, Taylor RE, Pearson AD and Clifford SC; United Kingdom Children's Cancer Study Group Brain Tumour Committee: beta-Catenin status predicts a favorable outcome in childhood medulloblastoma: The United Kingdom Children's Cancer Study Group Brain Tumour Committee. J Clin Oncol 23: 7951-7957, 2005.

37. Chmara M, Wernstedt A, Wasag B, Peeters H, Renard M, Beert E, Brems H, Giner T, Bieber I, Hamm H, et al: Multiple pilomatricomas with somatic CTNNB1 mutations in children with constitutive mismatch repair deficiency. Genes Chromosomes Cancer 52: 656-664, 2013.

38. Silva RD, Marie SK, Uno M, Matushita H, Wakamatsu A, Rosemberg S and Oba-Shinjo SM: CTNNB1, AXIN1 and APC expression analysis of different medulloblastoma variants. Clinics (Sao Paulo) 68: 167-172, 2013.

This work is licensed under a Creative Commons Attribution-NonCommercial-NoDerivatives 4.0 International (CC BY-NC-ND 4.0) License. 